\title{
Diabetes, hypertension and dyslipidemia medication prescribing in Qatari primary care settings: a retrospective analysis of electronic medical records
}

Mohamed Ahmed Syed ${ }^{1 *}$,, Ahmed Sameer Al Nuaimi ${ }^{1}$, Hamda Abdulla A/Qotba', Abduljaleel Abdullatif Zainel ${ }^{1}$, Tamara Marji' and Uzma Razaq ${ }^{2}$

\begin{abstract}
Background: Globally, non-communicable diseases (NCDs) are recognised as a leading cause of morbidity and mortality. Medications and medicines optimisation play an important role in the management of modifiable physiological risk factors and NCDs. The importance of lifestyle interventions in prevention of modifiable risk factors is also well established. The aim of this paper was to describe the quantity of type 2 diabetes mellitus (T2DM), hypertension and dyslipidaemia prescribing in Qatari primary care settings. Its findings will provide necessary information to inform pharmaceutical policy and practice.

Methods: The study was undertaken in Qatar's publicly funded primary health care centres. Data sources for this study comprised electronic medical records. The Anatomical Therapeutic Chemical (ATC) drug classification system was used to classify the medications prescribed. The number and proportion of medications by age, sex, nationality and diagnosis (T2DM, hypertension and dyslipidaemia) were reported.
\end{abstract}

Results: A total 81,569 individuals were included (18-29 years 2.4\%; 30-39 years 11.7\%; 40-49 years 25.4\%; $50-59$ years $31.9 \%$ and $\geq 60$ years $28.6 \%$ ). 55.6\% participants were male. On average 10.2 medications were prescribed per person and 2.3 medications were included in each prescription. T2DM medications were most prescribed $(N=361,87780,799 ; 43.2 \%)$ followed by hypertension $(N=303,086 ; 36.2 \%)$ and dyslipidaemia $(N=172,163 ; 20.5 \%)$. Of the total medications prescribed, $72 \%(N=605,488)$ were prescribed in individuals aged 50 years and above. Men were prescribed $62 \%(N=515,043)$ medications while women were prescribed $38 \%(N=322,083)$ medications. Southern Asians ( $N=330,338 ; 39 \%)$ were prescribed most medication followed by Qataris $(N=181,328 ; 22 \%)$ and Northern African ( $N=145,577 ; 17 \%)$.

Conclusions: In Qatar's primary care settings, average medications prescribed per patients were found to be higher compared to other populations. While medications were actively prescribed for the 3 conditions, the study found variations by medication type, age, gender and nationality. Rational guidelines for the utilisation of medications need to be established with the support of real-world evidence.

Keywords: Primary health care, Diabetes, Hypertension, Dyslipidaemia, Prescriptions, Qatar

*Correspondence: ahmed.sy3d@gmail.com

${ }^{1}$ Directorate of Clinical Affairs, Primary Health Care Corporation, P.O. Box 26555, Doha, Qatar

Full list of author information is available at the end of the article permits use, sharing, adaptation, distribution and reproduction in any medium or format, as long as you give appropriate credit to the original author(s) and the source, provide a link to the Creative Commons licence, and indicate if changes were made. The images or other third party material in this article are included in the article's Creative Commons licence, unless indicated otherwise in a credit line to the material. If material is not included in the article's Creative Commons licence and your intended use is not permitted by statutory regulation or exceeds the permitted use, you will need to obtain permission directly from the copyright holder. To view a copy of this licence, visit http://creativecommons.org/licenses/by/4.0/. The Creative Commons Public Domain Dedication waiver (http://creativeco mmons.org/publicdomain/zero/1.0/) applies to the data made available in this article, unless otherwise stated in a credit line to the data. 


\section{Background}

Globally, non-communicable diseases (NCDs) are recognised as a leading cause of morbidity and mortality. The burden of NCDs continues to increase in most countries. Aging, demographic transition, lifestyle changes, globalisation and urbanisation are factors that contribute to the increased prevalence, severity and complexity of NCDs [1].

Medications play a crucial role in maintaining health, preventing illness, managing chronic conditions [2]. However, there is a growing body of evidence suggesting a need to improve medicines use [2]. It is estimated that only $4 \%-21 \%$ of patients in primary care receive optimum benefit from their medicines [3]. 'Medicines optimisation' can be described as a system of processes and behaviours that determine how medicines are used in a health system for the safe and effective use of medicines to enable the best possible outcomes [4]. The goal of medicines optimisation is to help patients to improve their outcomes, take their medicines correctly, avoid taking unnecessary medicines, reduce wastage of medicines and improve medicines safety [5].

In Qatar, as in other countries, NCDs are a concern. A recent study reported $16.2 \%$ of the population in publicly funded primary care settings were diagnosed with one or more NCDs [6].

Modifiable physiological risk factors for NCDs were also reported to be high-insulin resistance $(60.3 \%)$, hypertension (53.5\%) and dyslipidaemia (48.5\%) [7]. Differences in prevalence by age, sex and nationality were reported $[6,7]$. The importance of lifestyle interventions in prevention of modifiable risk factors is well established [8-10]. Medications play an important role in the management of modifiable physiological risk factors and NCDs. Therefore, it is essential to optimise medications and encourage lifestyle interventions to improve health outcomes tailored to the population. This study aims is to describe the volume of type 2 diabetes mellitus (T2DM), hypertension and dyslipidaemia medications by age, sex and nationality in Qatari primary care settings. The study's findings provide necessary information to inform pharmaceutical policy and practice.

\section{Methods}

\section{Patient and public involvement}

Patients or the public were not involved in the design of the study.

\section{Study setting}

Qatar is a sovereign and independent state in the Middle East with a modern publicly funded healthcare system for Qataris and expatriates. This includes a universal primary care delivered by the Primary Health Care Corporation
(PHCC), the largest primary care provider in the country. As of June 2020, a total of 1,461,759 individuals (approximately $70 \%$ of the country's population) were registered across 27 PHCC health centres. Of these, 421, 283 individuals aged $\geq 18$ visited a health centre at least once between 1st January 2017 and 31st December 2017. All care is free of charge except medications which are heavily subsidised by the government.

\section{Study population and data collection}

Data source for this study comprised PHCC electronic medical records (EMR). The required data were extracted from the PHCC's EMR. PHCC has a single EMR system across all PHCC health centres. The study population included individuals meeting all of the following criteria (1) aged $\geq 18$ (2); visited a health centre between 1 st January 2017 and 31st December 2017; (3) had a diagnosis of T2DM, hypertension and/or dyslipidaemia and (4) were prescribed one or more medication for a diagnosis of T2DM, hypertension or dyslipidaemia.

\section{Definitions and data analysis}

For the purposes of this study, a 'clinical encounter' was defined as a clinical interaction between a patient and PHCC physician resulting in a prescription of a medication for one or more of the three diagnosis targeted in the study. Medications were defined as 'any chemical classified as a pharmaceutical compound under the Anatomical Therapeutic Chemical (ATC) classification and prescribed (as unique or refill prescriptions) to a patient for any one of the three diagnosis in a clinical encounter' while prescription were defined as 'one or more medications prescribed for a specific diagnosis in a clinical encounter.' A clinical encounter may have had 1, 2 or 3 prescriptions.

Variables for age, sex, nationality, diagnosis and medication prescribed for diagnosis were extracted from PHCC's EMR in an anonymised manner by the health information management department which oversees data recorded in the EMR. 'Statistical Package for the Social Sciences' statistical software package was used to analyse data collected. To analyse the population characteristics (age, sex and nationality; see online Table A in Additional file 1) and medications prescribed for three diagnoses-hypertension, T2DM and dyslipidaemia-basic descriptive statistics were used. The ATC drug classification system was used to classify the medications prescribed. In the ATC drug classification system, the medications are divided into different groups according to the organ or system on which they act and their therapeutic, pharmacological and chemical properties [11]. For the purposes of this study, ATC level 4 (code indicating the chemical/therapeutic/pharmacological 
subgroup and consisting of one letter) was counted as one medication.

To ensure the accuracy of the data, a two-stage validation process was undertaken. The codes used to extract data from the EMR were developed by a health information management specialist and reviewed by another specialist to ensure its accuracy in extracting the required dataset. A total of 201 unique medications (by generic name) were included in the dataset. They were categorised into the ATC classification independently by two consultants. Any discrepancies in selection were resolved through discussions at a consensus meeting.

\section{Ethical approval}

The data for the study were collected in an anonymised manner. None of the subjects' personal information was available to the research team. Overall, the study was conducted with integrity according to generally accepted ethical principles and was reviewed and approved under the exempt review category by the PHCC's ResearchSubcommittee (PHCC/RS/18/02/003).

\section{Results}

\section{Population characteristics}

The study included a total 81,569 individuals who were diagnosed with one or more of the following-T2DM, hypertension and dyslipidaemia (see Table 1). Majority by

Table 1 Population characteristics

\begin{tabular}{|c|c|c|}
\hline & $N$ & $\begin{array}{l}\% \\
\text { (total } \\
N=81,569 \text { ) }\end{array}$ \\
\hline \multicolumn{3}{|l|}{ Age (years) } \\
\hline $18-29$ & 1939 & 2.4 \\
\hline $30-39$ & 9523 & 11.7 \\
\hline $40-49$ & 20,757 & 25.4 \\
\hline $50-59$ & 26,031 & 31.9 \\
\hline$\geq 60$ & 23,319 & 28.6 \\
\hline \multicolumn{3}{|l|}{ Sex } \\
\hline Female & 36,180 & 44.4 \\
\hline Male & 45,389 & 55.6 \\
\hline \multicolumn{3}{|l|}{ Nationality } \\
\hline Qatar & 22,003 & 27.0 \\
\hline Northern Africa & 13,404 & 16.4 \\
\hline Sub-Saharan Africa & 947 & 1.2 \\
\hline Northern America & 486 & 0.6 \\
\hline South-eastern Asia & 5638 & 6.9 \\
\hline Southern Asia & 27,783 & 34.1 \\
\hline Western Asia (excluding Qatar) & 10,704 & 13.1 \\
\hline All others & 603 & 0.7 \\
\hline
\end{tabular}

nationality were Southern Asian or Qatari $(N=49,786$; $61 \%)$ and by age over 40 years $(N=70,107 ; 85.9 \%)$.

\section{Overall medications prescribed}

A total of 837,126 medications were prescribed using 359,079 prescriptions for 81,569 individuals (see Table 2). T2DM medications were most prescribed $(N=361,877$; $43.2 \%)$ followed by hypertension $(N=303,086 ; 36.2 \%)$ and dyslipidaemia $(N=172,163 ; 20.5 \%)$. The most commonly prescribed medications were HMG-CoA reductase inhibitors [C10AA]- (also known as statins) $(N=169,301 ; 20.2 \%)$, biguanides [A10BA]- $(N=115,690$; $13.8 \%$, sulfonamides [A10BB]- (urea derivatives) $(N=88,935 ; 10.6 \%)$ and angiotensin-converting enzyme inhibitors [C09AA]- (plain) $(N=69,409 ; 8.3 \%)$ accounting for $52.9 \%(N=443,335)$ of all medications prescribed (see Table 3).

On average 10.2 medications were prescribed per person during the study period (3.7 hypertension medications per person; 4.3 T2DM medications; 2.1 dyslipidaemia medications per person) and 2.3 medications were included in each prescription $(0.8$ hypertension medication per prescription; 1 T2DM medication per prescription; 0.5 hypertension medication per prescription).

\section{Medications prescribed by age}

Of the total medications $(N=837,126)$ prescribed, $72 \%(N=605,488)$ were prescribed in individuals aged 50 years and above. In $18-29$ year olds, $72 \%(N=4,664)$ medications prescribed were for T2DM. Majority of individuals aged 30 years and above were prescribed T2DM medications $(39.9 \%-53.5 \%)$ followed by hypertension $(31.3 .4 \%-39.4 .1 \%)$ and dyslipidaemia medications (16.3\%-21.7\%) (see Table 4). Biguanides (29.7\%) followed by insulins and analogues for injection (long-acting) (12.4\%) and insulins and analogues for injection (fastacting) (11.8\%) were most prescribed medications in 18-29 year olds. In 30-39 year olds, biguanides (20.2\%) followed by statins $(16 \%)$ and sulfonamides (urea derivatives) (10.8\%) were most prescribed. Statins (20\%-21.3\%) followed by biguanides $(11.8 \%-15.5 \%)$ and sulfonamides

Table 2 Prescriptions by diagnosis

\begin{tabular}{ll}
\hline Diagnosis & $\begin{array}{l}\text { Prescriptions } \\
\mathbf{N}(\%)\end{array}$ \\
\hline Hypertension & $145,546(40.5)$ \\
T2DM & $136,569(38.0)$ \\
Dyslipidaemia & $76,964(21.4)$ \\
Total & 359,079 \\
\hline
\end{tabular}


Table 3 Overall medications prescribed

\begin{tabular}{|c|c|c|c|c|}
\hline Diagnosis & Medication & ATC code & $\mathbf{N}$ & $\%$ \\
\hline \multirow[t]{17}{*}{ Hypertension } & Angiotensin-converting enzyme inhibitors, plain & [CO9AA]- & 69,409 & 8.3 \\
\hline & Dihydropyridine derivatives & [C08CA]- & 55,356 & 6.6 \\
\hline & Angiotensin II antagonists, plain & [CO9CA]- & 40,709 & 4.9 \\
\hline & Beta blocking agents, plain, selective & [C07AB]- & 31,336 & 3.7 \\
\hline & Angiotensin-converting enzyme inhibitors and diuretics & [CO9BA]- & 24,463 & 2.9 \\
\hline & Angiotensin II antagonists and diuretics & [CO9DA]- & 21,569 & 2.6 \\
\hline & $\begin{array}{l}\text { Angiotensin-converting enzyme inhibitors and calcium channel } \\
\text { blockers }\end{array}$ & [CO9BB]- & 15,887 & 1.9 \\
\hline & Sulfonamides, plain (low ceiling diuretics) & {$[\mathrm{CO3BA}]-$} & 15,143 & 1.8 \\
\hline & Angiotensin II antagonists and calcium channel blockers & [C09DB]- & 14,710 & 1.8 \\
\hline & Sulfonamides, plain (high ceiling diuretics) & {$[\mathrm{CO} C \mathrm{CA}]-$} & 3779 & 0.4 \\
\hline & Alpha and beta blocking agents & [C07AG]- & 3178 & 0.4 \\
\hline & Beta blocking agents, selective, and thiazides & [CO7BB]- & 2308 & 0.3 \\
\hline & Thiazides, plain & {$[\mathrm{CO3AA}]-$} & 2038 & 0.2 \\
\hline & Beta blocking agents, plain, non-selective & [CO7AA]- & 1654 & 0.2 \\
\hline & Clonidine and analogues & {$[\mathrm{CO} 2 \mathrm{AC}$} & 849 & 0.1 \\
\hline & Methyldopa & {$[\mathrm{CO} 2 \mathrm{AB}]-$} & 698 & 0.1 \\
\hline & Total & & 303,086 & 36.2 \\
\hline \multirow[t]{13}{*}{ T2DM } & Biguanides & {$[\mathrm{A} 10 \mathrm{BA}]-$} & 115,690 & 13.8 \\
\hline & Sulfonamides, urea derivatives & [A10BB]- & 88,935 & 10.6 \\
\hline & Combinations of oral blood glucose lowering drugs & {$[\mathrm{A} 10 \mathrm{BD}]-$} & 62,340 & 7.4 \\
\hline & Insulins and analogues for injection, long-acting & [A10AE]- & 28,457 & 3.4 \\
\hline & Dipeptidyl peptidase 4 (dpp-4) inhibitors & {$[\mathrm{A} 10 \mathrm{BH}]-$} & 25,246 & 3.0 \\
\hline & $\begin{array}{l}\text { Insulins and analogues for injection, intermediate-acting combined } \\
\text { with fast-acting }\end{array}$ & [A10AD]- & 13,686 & 1.6 \\
\hline & Insulins and analogues for injection, fast-acting & {$[A 10 A B]-$} & 11,594 & 1.4 \\
\hline & Thiazolidinediones & {$[\mathrm{A} 10 \mathrm{BG}$} & 11,405 & 1.4 \\
\hline & Insulins and analogues for injection, intermediate-acting & {$[A 10 A C]-$} & 2688 & 0.3 \\
\hline & Other oral blood glucose lowering drugs & {$[\mathrm{A} 10 \mathrm{BX}]-$} & 1095 & 0.1 \\
\hline & Glucagon-like peptide-1 (GLP-1) analogues & [A10BJ]- & 433 & 0.1 \\
\hline & Alpha glucosidase inhibitors & [A10BF]- & 308 & 0.0 \\
\hline & Total & & 361,877 & 43.2 \\
\hline \multirow[t]{4}{*}{ Dyslipidaemia } & HMG-CoA reductase inhibitors & {$[\mathrm{C} 10 \mathrm{AA}]-$} & 169,301 & 20.2 \\
\hline & Other lipid modifying agents & {$[\mathrm{C} 10 \mathrm{AX}]-$} & 2679 & 0.3 \\
\hline & Fibrates & [C10AB]- & 183 & 0.0 \\
\hline & Total & & 172,163 & 20.5 \\
\hline Grand total & & & 837,126 & \\
\hline
\end{tabular}

Table 4 Medications prescribed by age

\begin{tabular}{|c|c|c|c|c|c|c|c|c|c|c|}
\hline \multirow[t]{2}{*}{ Diagnosis } & \multicolumn{2}{|c|}{$18-29$} & \multicolumn{2}{|l|}{$30-39$} & \multicolumn{2}{|l|}{$40-49$} & \multicolumn{2}{|l|}{$50-59$} & \multicolumn{2}{|l|}{$\geq 60$} \\
\hline & $(N)$ & (\%) & $(N)$ & (\%) & $(N)$ & (\%) & $(N)$ & (\%) & $(N)$ & (\%) \\
\hline Hypertension & 1291 & 20 & 16,505 & 31.3 & 59,403 & 34.5 & 103,941 & 35.1 & 121,946 & 39.4 \\
\hline $\mathrm{T} 2 \mathrm{DM}$ & 4664 & 72.1 & 27,687 & 52.5 & 77,989 & 45.2 & 128,017 & 43.2 & 123,520 & 39.9 \\
\hline Dyslipidaemia & 515 & 8 & 8586 & 16.3 & 34,998 & 20.3 & 64,112 & 21.7 & 63,952 & 20.7 \\
\hline Total & 6470 & & 52,778 & & 172,390 & & 296,070 & & 309,418 & \\
\hline
\end{tabular}


(urea derivatives) (9.8\%-11.6\%) were most commonly prescribed in individuals aged 40 and above (see online Table B in Additional file 1).

\section{Medications prescribed by sex}

Men were prescribed 62\% $(N=515,043)$ medications while women were prescribed $38 \%(N=322,083)$ medications (see Table 5). T2DM medications were most commonly prescribed for both men and women $(N=229,596$; $44.6 \%$ and $N=132,281 ; 41.1 \%$, respectively) followed by hypertension $(N=178,544 ; 34.7 \%$ and $N=124,542$; $38.7 \%$, respectively) and dyslipidaemia ( $N=106,903$; $20.8 \%$ and $N=65,260 ; 20.3 \%$, respectively) medications (see online Table C in Additional file 1).

\section{Medications prescribed by nationality}

Southern Asians $(N=330,338 ; 39 \%)$ were prescribed most medication followed by Qataris $(N=181,328 ; 22 \%)$ and Northern African $(N=145,577 ; 17 \%)$ (see Table 6). The most commonly prescribed medication amongst South-eastern Asians $(N=25,335 ; 59.2 \%)$, Northern Americans $(N=1,921 ; 39.8 \%)$ and Western Asians $(N=45,342 ; 38 \%)$ was for hypertension. The most commonly prescribed medication amongst Southern Asians $(N=153,621 ; 46.5 \%)$, Qataris $(N=81,933 ; 45.2 \%)$, Northern Africans $(N=63,357 ; 43.5 \%)$ and sub-Saharan Africans $(N=3,548 ; 42.8 \%)$ was for T2DM (see online Table $\mathrm{D}$ in Additional file 1).

Table 5 Medications by sex

\begin{tabular}{|c|c|c|c|c|}
\hline & \multicolumn{2}{|l|}{ Female } & \multicolumn{2}{|l|}{ Male } \\
\hline & $N$ & $\%$ & $N$ & $\%$ \\
\hline Hypertension & 124,542 & 38.7 & 178,544 & 34.7 \\
\hline $\mathrm{T} 2 \mathrm{DM}$ & 132,281 & 41.1 & 229,596 & 44.6 \\
\hline Dyslipidaemia & 65,260 & 20.3 & 106,903 & 20.8 \\
\hline Total & 322,083 & & 515,043 & \\
\hline
\end{tabular}

\section{Discussion}

\section{Summary}

The study found a total of 837,126 medications were prescribed using 359,079 prescriptions for 81,569 individuals, an average of 10.2 medications per patient. This is higher in comparison to a Swedish study which reported an average of 2.3 medications per person in chronic disease patients aged 25-70 years [12] and a Saudi Arabian study which reported an average of 6.4 medications per person in chronic disease patients aged 65-70 years [13]. This study, to the authors' knowledge, is the first such comprehensive study in the Middle East. It adds valuable insight on prescribing patterns in primary settings for T2DM, hypertension and dyslipidaemia which have an increasing burden in Qatar and also in the Middle East [14]. Its findings will help optimise prescribing and medicines management in patients with one or more of the diagnosis.

\section{Strengths and limitations}

The study's strength includes a large sample and reliable data extracted from an EMR system. This facilitates development of strategies related to medicines and provide a baseline for future research.

The limitations of the study include the following: a cross-sectional study design which provides a snapshot in time. Furthermore, the study only included patients who were 18 years and above and those who attended a PHCC health centre in 2017. Therefore, the findings of the study cannot be considered comprehensive and nationally representative.

\section{Comparison with existing literature}

The study found T2DM medications were most prescribed (43.2\%) followed by hypertension (36.2\%) and dyslipidaemia (20.5\%). In terms of individual medication, statins were most commonly prescribed medications (20.2\%). However, a recent study reported a gap between guidelines and practice in the management of dyslipidaemia in the Middle East [15]. Ensuring that individuals

Table 6 Medications by nationality categories

\begin{tabular}{|c|c|c|c|c|c|c|c|c|c|c|c|c|c|c|c|c|}
\hline & \multicolumn{2}{|l|}{ Qatar } & \multicolumn{2}{|c|}{$\begin{array}{l}\text { Northern } \\
\text { Africa }\end{array}$} & \multicolumn{2}{|c|}{$\begin{array}{l}\text { Sub- } \\
\text { Saharan } \\
\text { Africa }\end{array}$} & \multicolumn{2}{|c|}{$\begin{array}{l}\text { Northern } \\
\text { America }\end{array}$} & \multicolumn{2}{|c|}{$\begin{array}{l}\text { South- } \\
\text { eastern Asia }\end{array}$} & \multicolumn{2}{|c|}{ Southern Asia } & \multicolumn{2}{|c|}{$\begin{array}{l}\text { Western Asia } \\
\text { (excluding } \\
\text { Qatar) }\end{array}$} & \multicolumn{2}{|c|}{ All others } \\
\hline & $N$ & $\%$ & $N$ & $\%$ & $N$ & $\%$ & $N$ & $\%$ & $N$ & $\%$ & $N$ & $\%$ & $N$ & $\%$ & $N$ & $\%$ \\
\hline Hypertension & 61,210 & 33.8 & 52,468 & 36 & 3378 & 40.8 & 1921 & 39.8 & 25,335 & 59.2 & 111,389 & 33.7 & 45,342 & 38 & 2043 & 42.8 \\
\hline T2DM & 81,933 & 45.2 & 63,357 & 43.5 & 3548 & 42.8 & 1577 & 32.7 & 9607 & 22.4 & 153,621 & 46.5 & 46,921 & 39.4 & 1312 & 27.5 \\
\hline Dyslipidaemia & 38,185 & 21.1 & 29,752 & 20.4 & 1358 & 16.4 & 1325 & 27.5 & 7888 & 18.4 & 65,328 & 19.8 & 26,914 & 22.6 & 1413 & 29.6 \\
\hline Total & 181,328 & & 145,577 & & 8284 & & 4823 & & 42,830 & & 330,338 & & 119,177 & & 4768 & \\
\hline
\end{tabular}

Refer to additional file for nationality classification 
diagnosed with dyslipidaemia are prescribed medications in accordance to issued guidelines is essential. [7]. Similarly, medications for hypertension and insulin resistance should also be in line with issued guidelines as prevalence of hypertension was reported to be higher than dyslipidaemia $-53 \%$ and $60.3 \%$ [7]. A review by Al-Maatouq et al. found metformin, a biguanide, to be used less frequently to initiate antidiabetic therapy in the Middle East than in other countries [16].

Seventy-two percent of medications prescribed were in individuals aged 50 and above in this study. Men were prescribed more medications than women $(62 \%$ and $38 \%$, respectively). In a Flemish-Belgian study, $54.8 \%$ of individuals aged 50 and above were prescribed medications. Men and women were prescribed almost similar amounts of medications (56.8\% and $52.9 \%$, respectively) [17]. Figures from this study show more medications were prescribed in individuals aged 50 years and above. Furthermore, men are prescribed more medication than women. This may be due to the fact that men have higher prevalence of non-communicable diseases compared to women in Qatar [6].

Southern Asians, Qataris and Northern African were prescribed most medications (39\%, 22\% and 17\%). These nationalities were the largest nationality groups in the study and the same nationality groups were found to have the highest prevalence of metabolic syndrome [7] and non-communicable diseases in the population [6]. This is a possible explanation for the prescribing pattern seen in these nationality groups.

\section{Conclusions}

In Qatar's primary care settings, average medications prescribed per patients were found to higher compared to other populations. While medications are actively prescribed for the 3 conditions, study found variations by medication type, age, gender and nationality. Rational guidelines for the utilisation of medications need to be established with the support of real-world evidence.

\section{Abbreviations}

NCDs: Non-communicable diseases; T2DM: Type 2 diabetes mellitus; ATC: Anatomical Therapeutic Chemical; EMR: Electronic medical records; PHCC: Primary Health Care Corporation; WHOCC: World Health Organization Collaborating Centre for Drug Statistics.

\section{Supplementary Information}

The online version contains supplementary material available at https://doi. org/10.1186/s40545-021-00353-4.

Additional file 1. Additional tables.

\section{Acknowledgements}

The authors would like to thank Ms. Hanan Khudadad for assistance with using a reference management software for the manuscript.

\section{Authors' contributions}

MAS and ASAN contributed to the design of the study. ASAN undertook data extraction and analysis. MAS and UR prepared the first draft of the manuscript. ASAN, HAQ. AAZ, TM and UR reviewed, edited and approved the final version of the manuscript. MAS designed the study. ASAN undertook data extraction and analysis. MAS drafted the manuscript. All authors read and approved the final manuscript.

\section{Funding}

Not applicable.

\section{Availability of data and materials}

The datasets used and/or analysed during the current study available from the corresponding author on reasonable request.

\section{Declarations}

\section{Ethics approval and consent to participate}

Overall, the study was conducted with integrity according to generally accepted ethical principles and was reviewed and approved under the exempt review category by the PHCC's Research-Subcommittee (PHCC/ $\mathrm{RS} / 18 / 02 / 003)$.

\section{Consent for publication}

Not applicable.

\section{Competing interests}

The authors declare that they have no competing interests.

\section{Author details}

${ }^{1}$ Directorate of Clinical Affairs, Primary Health Care Corporation, P.O. Box 26555, Doha, Qatar. ${ }^{2}$ Directorate of Clinical Operations, Primary Health Care Corporation, P.O. Box 26555, Doha, Qatar.

Received: 2 May 2021 Accepted: 29 July 2021

Published online: 11 August 2021

\section{References}

1. Widyahening IS. The role of primary health care in the prevention of noncommunicable diseases. Rev Prim Care Prac and Educ. 2019;2(1):5-7.

2. Royal Pharmaceutical Society. Medicines Optimisation:Helping patients to make the most of medicines Available from https://www.rpharms. com/Portals/0/RPS\%20document\%20library/Open\%20access/Policy/ helping-patients-make-the-most-of-their-medicines.pdf. Accessed 06 June 2021.

3. Garfield S, Barber N, Walley P, et al. Quality of medication use in primary care-mapping the problem, working to a solution: a systematic review of the literature. BMC Med. 2009;7:50. https://doi.org/10.1186/ 1741-7015-7-50.

4. National Institute for Health and Care Excellence. Medicines optimisation: the safe and effective use of medicines to enable the best possible outcomes. NICE guidelines [NG5], 2015.

5. NHS England. Medicines optimisation. Available from https://www.engla nd.nhs.uk/medicines-2/medicines-optimisation/. Accessed 06 June 2021.

6. Syed MA, Alnuaimi AS, Zainel AJ, et al. Prevalence of non-communicable diseases by age, gender and nationality in publicly funded primary care settings in Qatar. BMJ Nutr Prev Health. 2019. https://doi.org/10.1136/ bmjnph-2018-000014.

7. Syed MA, Alnuaimi AS, Zainel AJ, et al. Prevalence of Metabolic Syndrome in Primary Health settings in Qatar: a cross sectional study. BMC Public Health. 2020;20:611. https://doi.org/10.1186/s12889-020-08609-5. 
8. Davis JC, Verhagen E, Bryan S, et al. 2014 consensus statement from the first Economics of Physical Inactivity Consensus (EPIC) conference (Vancouver). Br J Sports Med. 2014;48(12):947-51. https://doi.org/10.1136/ bjsports-2014-093575.

9. Ezzati M, Riboli E. Can noncommunicable diseases be prevented? Lessons from studies of populations and individuals. Science. 2012;337(6101):1482-7. https://doi.org/10.1126/science.1227001.

10. Kontis $V$, Mathers CD, Rehm J, et al. Contribution of six risk factors to achieving the $25 \times 25$ non-communicable disease mortality reduction target: a modelling study. Lancet. 2014;384(9941):427-37. https://doi.org/ 10.1016/s0140-6736(14)60616-4.

11. WHO Collaborating Centre for Drug Statistics Methodology. The Anatomical Therapeutic Chemical Classification System with Defined Daily Doses (ATC/DDD): World Health Organization 2003 [cited 2020 10/03/2020]. https://www.who.int/standards/classifications/other-classifications/ the-anatomical-therapeutic-chemical-classification-system-with-defineddaily-doses. Accessed 06 June 2021.

12. Hagstrom B, Mattsson B, Wimo A, et al. More illness and less disease? A 20-year perspective on chronic disease and medication. Scand J Public Health. 2006:34(6):584-8. https://doi.org/10.1080/14034940600703407.

13. Alsuwaidan A, Almedlej N, Alsabti S, et al. A comprehensive overview of polypharmacy in elderly patients in Saudi Arabia. Geriatrics. 2019;4:2. https://doi.org/10.3390/geriatrics4020036.
14. Rahim HF Sibai A, Khader Y et al. Non-communicable diseases in the Arab world. Lancet. 2014;383(9914):356-67. https://doi.org/10.1016/ s0140-6736(13)62383-1.

15. Al Rasadi K, Almahmeed W, AlHabib KF, et al. Dyslipidaemia in the Middle East: Current status and a call for action. Atherosclerosis. 2016;252:182-7. https://doi.org/10.1016/j.atherosclerosis.2016.07.925.

16. Al-Maatoug M, Al-Arouj M, Assaad SH, et al. Optimising the medical management of hyperglycaemia in type 2 diabetes in the Middle East: pivotal role of metformin. Int J Clin Pract. 2010;64(2):149-59. https://doi.org/10. 1111/j.1742-1241.2009.02235.x.

17. van den Akker M, Vaes B, Goderis G, et al. Trends in multimorbidity and polypharmacy in the Flemish-Belgian population between 2000 and 2015. PLOS ONE. 2019;14(2):e0212046. https://doi.org/10.1371/journal. pone.0212046.

\section{Publisher's Note}

Springer Nature remains neutral with regard to jurisdictional claims in published maps and institutional affiliations.
Ready to submit your research? Choose BMC and benefit from:

- fast, convenient online submission

- thorough peer review by experienced researchers in your field

- rapid publication on acceptance

- support for research data, including large and complex data types

- gold Open Access which fosters wider collaboration and increased citations

- maximum visibility for your research: over $100 \mathrm{M}$ website views per year

At BMC, research is always in progress.

Learn more biomedcentral.com/submissions 